\title{
Correction to: Low insertion of cystic duct increases risk for common bile duct stone recurrence
}

\author{
Seong Ji Choi ${ }^{1}$. Jai Hoon Yoon ${ }^{1}$ Dong Hee Koh ${ }^{2} \cdot$ Hang Lak Lee $^{1} \cdot$ Dae Won Jun ${ }^{1} \cdot$ Ho Soon Choi ${ }^{1}$
}

Published online: 22 July 2021

(c) The Author(s), under exclusive licence to Springer Science+Business Media, LLC, part of Springer Nature 2021

\section{Correction to: Surgical Endoscopy}

https://doi.org/10.1007/s00464-021-08563-2

This article was updated to correct author name Jai Hoon

Yoon (first name: Jai Hoon, family name: Yoon).

Publisher's Note Springer Nature remains neutral with regard to jurisdictional claims in published maps and institutional affiliations.

The original article can be found online at https://doi.org/10.1007/ s00464-021-08563-2.

Jai Hoon Yoon

jaihoonyoon@hanyang.ac.kr

1 Department of Internal Medicine, Hanyang University

College of Medicine, 222-1 Wangsimni-ro, Seongdong-gu,

Seoul 04763, Republic of Korea

2 Division of Gastroenterology, Department of Internal Medicine, Hallym University Dongtan Sacred Heart

Hospital, Hallym University College of Medicine,

Hwaseong 18450, Republic of Korea 